\title{
In honor of the 80th birthday of Kurt Jellinger: a living legend in neuropathology
}

\author{
Hans Lassmann • Christian Bancher • \\ Johannes Attems $\cdot$ Werner Paulus
}

Published online: 27 April 2011

(C) Springer-Verlag 2011

Professor Kurt Jellinger is, without any doubt, one of the most eminent neuropathologists of our current times. Born in Vienna, Austria, on May 28, 1931 to Rosa and Alois Jellinger (Fig. 1), he studied medicine at the Medical Faculty of the University of Vienna and received his promotion to Dr. med. univ. "sub auspiciis praesidentis" in April 1956. His primary medical training was in clinical neurology to become a board-certified neurologist in 1963 . In parallel, he was trained in neuropathology at the Neurological Institute of the University of Vienna (Fig. 2) under the guidance of Franz Seitelberger. Following his promotion to reader for Neurology, Neuropathology and Neuroanatomy at the University of Vienna in 1967, he became Head of the Neuropathological Department of the Neurological Institute and a.o. University Professor for Neuropathology in 1973. His high international reputation resulted in several international offers to take over full Professorships in Germany (Düsseldorf) and the United States (Miami, Cleveland), which he all declined. Instead, he decided to accept the position as Head of the

\footnotetext{
H. Lassmann

Center for Brain Research, Medical University of Vienna,

Vienna, Austria

C. Bancher

Department of Neurology, Landesklinikum Waldviertel

Horn-Allentsteig, Horn, Austria

J. Attems

Institute for Ageing and Health, Newcastle University,

Newcastle upon Tyne, UK

W. Paulus $(\bowtie)$

Institute of Neuropathology, University Hospital Münster,

Domagkstr. 19, 48129 Münster, Germany

e-mail: werner.paulus@uni-muenster.de
}

Department of Neurology at the Viennese Municipal Hospital Lainz in 1976 and the Directorship of the Ludwig Boltzmann Institute for Clinical Neurobiology, located in the same building (1977). He held both positions until his retirement in the 1990s.

Kurt Jellinger is an outstanding member of many scientific societies and he continues to be among the most active participants of important scientific meetings (Fig. 3). He co-organized the First European Congress of Neuropathology in Vienna in 1980 and the 9th International Congress of Neuropathology in Vienna in 1982, serving as Vice President of the International Society of Neuropathology from 1981 to 1984 . Being highly respected in both neuropathology and neurology, he was President of the Austrian Society of Neurology and Psychiatry (1990-1992) and President of the Austrian Society of Neuropathology (1994-1998). Needless to say that Kurt Jellinger has been elected an honorary member of several national and international societies.

Kurt Jellinger's contributions to neuropathological science are enormous. The ISI Web of Knowledge reports 698 papers with an h-index of 71 and an average number of citations of $32.5,50$ of his publications being citation classics receiving more than 100 citations so far, the most prominent ones being related to Alzheimer's and Parkinson's diseases. This is supplemented by a large number of additional publications in conference proceedings and book chapters. Thus, his predominant focus of research is in the area of neurodegenerative diseases. However, this gives only an incomplete impression of his scientific activity. There is virtually no field of neuropathology that is not covered by fundamental publications of Kurt Jellinger, including neuroanatomy, neurotraumatology, vascular diseases, infectious diseases of the nervous system, multiple sclerosis, developmental disorders of the brain, and 
neurooncology. Most of his studies focused on the clinical relevance of neuropathological findings. In addition, Kurt Jellinger is also a pioneer in combining biochemical and neuropathological approaches to elucidate disease mechanisms. Particularly illustrative examples for this approach are his highly cited publications on brain dopamine in Parkinson's disease, published together with Hanno Bernheimer and Oleh Hornykiewicz, and on studies in

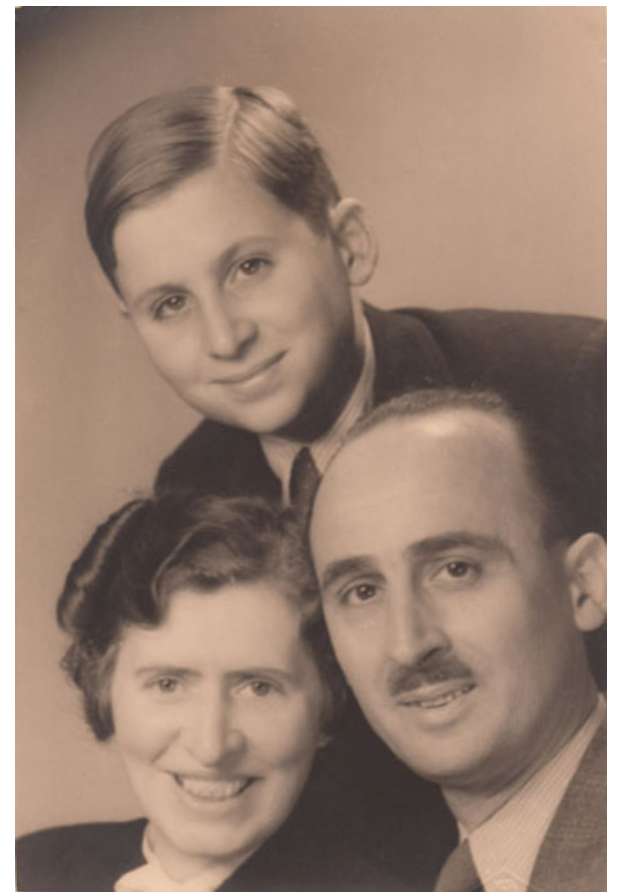

Fig. 1 Kurt Jellinger with his parents Rosa and Alois Jellinger

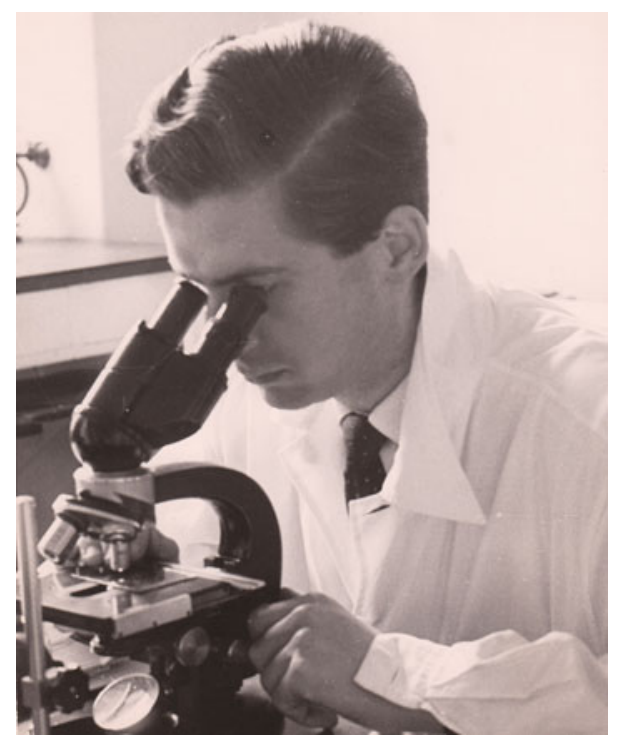

Fig. 2 At work at the Neurological Institute, University of Vienna

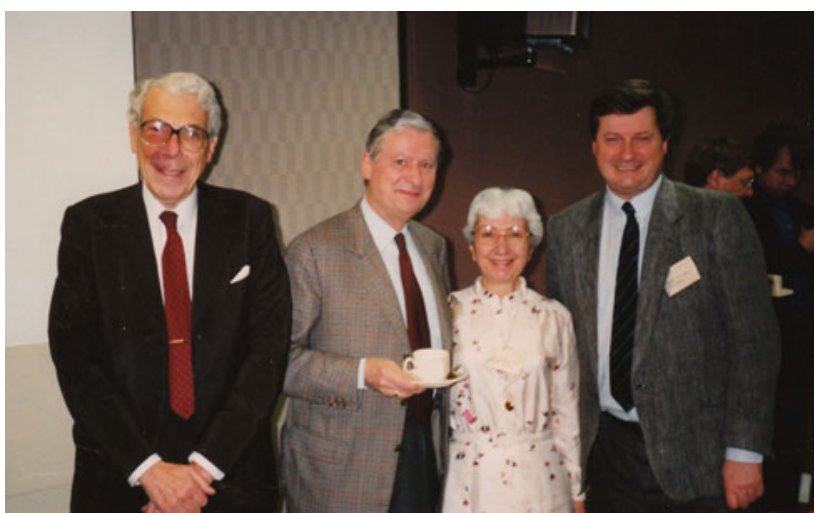

Fig. 3 At a brain tumor meeting with Lucien Rubinstein, Lucy Rorke, and Paul Kleihues

collaboration with Peter Riederer, who was, for a long time, part of his team at Lainz Hospital.

Very early in his career, Kurt noticed that human neuropathology is highly complex and that definite conclusions regarding both clinical and pathophysiological meaning of tissue alterations can only be reached when sufficient numbers of cases are studied in a broad manner. Thus, he developed a sort of obsession in collecting tissue for neuropathological assessment. He did that by extending his autopsy service to several additional institutions outside of Vienna. At that time, travel in general was done by train and not by car, and on his return to Vienna, his railway compartment was filled with freshly dissected brains, soaked in formalin solution. Under these circumstances, co-travelers in general avoided to join him in his compartment, giving him plenty of quiet time to keep up with his duties as the Editor of Acta Neuropathologica.

An especially amazing gift of Kurt Jellinger is his enormous capacity in optical and verbal memory. This made his brain dissection sessions (Fig. 4) particularly memorable. For young trainees like me (HL), it was unbelievable how quickly one could grasp morphological alterations in a dissected brain and translate this into a dictated neuropathological report. Even more amazing was his reaction to specific neuropathological questions. The question was not only answered in substance, but the answer also contained a long list of respective references with titles, authors, year and journal of publication, and other citation details, which all came out of this impressive memory. In times preceding Medline or other literature databases, this was an extremely valuable resource, which saved hours of intense literature search. On a similar basis, he was also the only person in the institute who exactly knew what was hidden in the enormous neuropathological archives, kept in the cellar of the building. Whenever he was confronted with a newly described neuropathological entity, he immediately came up with a long list of case 


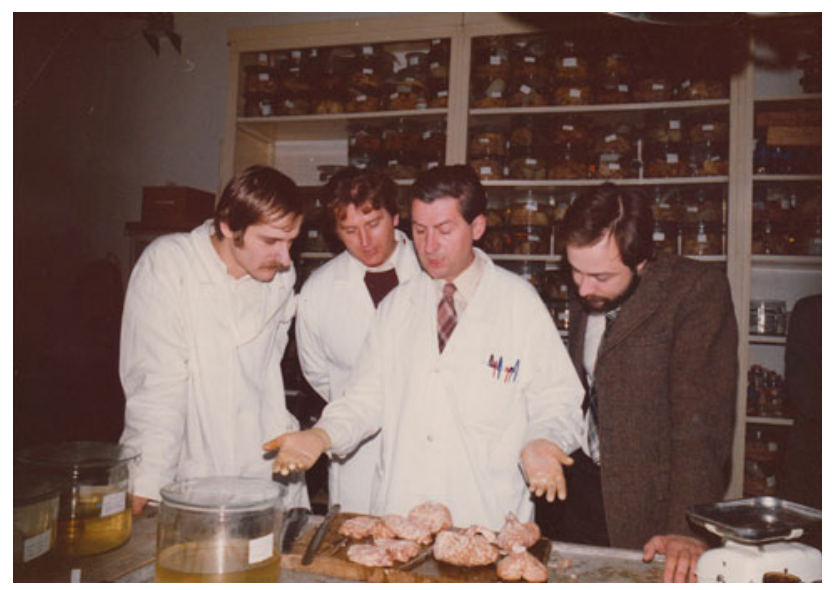

Fig. 4 Brain cutting session led by Kurt Jellinger, attended (from left) by Drs. Hans Lassmann, Georg Wöber (neurosurgery), and Georg Spiel (pediatric neurology and psychiatry)

numbers referring to autopsy cases with similar pathological alterations that were stored in the archive. For a long time, I thought that this information was exclusively stored in his memory. However, much later, I realized that this was at least partly based on a card index system, consisting of numerous small cards fully filled with numbers and symbols, where he was the sole person able to grasp their meaning. All of these gifts made Kurt Jellinger a formidable teacher, which was of particular importance in the 1970s, a time when comprehensive textbooks of neuropathology were sparse or absent.

While in the scientific world Kurt Jellinger is known as one of the greatest neuropathologists and neuroscientists of our time, many colleagues outside of his home country may not realize that Kurt is a very active clinician as well. I (CB) got the opportunity to join the Department of Neurology in Lainz for my residency in neurology in the early 1990s. We were a team of 12 physicians. As the head of department, Kurt treated us like a father. And this was only natural, as his experience and knowledge were clearly in other dimensions than those of my colleagues and myself. Whenever possible, he used his medical and political influence in our favor. Even though it used to be a bad idea to drop into his office without having an appointment-his time schedule was tightly packed-one could be sure that one's problem would be cared for, usually in a much shorter period of time than initially expected. I remember having been kicked out of his office on an early afternoon; my intention was to ask about a medium-sized administrative matter. Depressed and believing that my problem would probably not be considered at all, I went to leave later in the afternoon. Was it by chance that I met Kurt in the corridor on the way home? As a matter of fact, he just told me within a few seconds that he had taken the necessary steps in the meantime and that everything was just fine; before I could express my gratitude, he disappeared just as quickly.

Kurt went on the clinical rounds once or twice a week, usually quite quickly. This had to be as efficient as anything else, and it was astonishing how much he knew about patients whom he had never seen before, both in terms of medical details, but also concerning social and private matters. It must have been his astonishing memory that allowed him to remember all of the details from the daily morning meetings that took place in his office, at eight o'clock sharp. His office was a relatively large, sparsely furnished room with a desk, a sofa, and a huge closet covering the entire height of the room, over a distance of more than $10 \mathrm{~m}$. This treasury of neurological and neuropathological state-of-the-art literature contained journals, books, and publications on all areas of neurology and neuropathology and was astonishingly up to date, long before the time of the Internet and e-mail. It was with amazing speed, and without hesitation, that Kurt took out of this collection the most recent and relevant publication if a medical question on a patient arose. No time to lose for teaching in words, but plenty of written information to talk about in a few words, which gave you answers in much more detail. "Nothing to put under one's pillow to sleep on it", as he used to say, but literature to share to be able to speak the same language. Not everybody in the department shared Kurt's scientific interests. This was accepted and respected, and each of the colleagues had his or her own little area of specialization. Kurt is very broad-minded, and acupuncture had its place as well as the core neurological diagnostic and therapeutic tools. Besides the clinic, Kurt ran his private practice (and still does) on one afternoon in the week and he served as the court-certified expert on a regular basis. So, his clinical duties were broad, as broad as his scientific interests.

Adjoined to the clinic was the Ludwig Boltzmann Institute of Clinical Neurobiology, the setting in which the brain cutting sessions took place and where histology, cerebrospinal fluid cytology, immunocytochemistry, and electron microscopic work was done. It was located in the same building, with the clinic on the ground floor and science two floors up within a geriatric ward. Kurt used to pick up several brains each morning at the nearby mortuary of the Institute of Pathology and carried them in plastic buckets (the organ being well recognizable from outside) over the ward into the dissection room. While demented patients who had lost their way occasionally wandered in during brain cutting, few of the clinicians made their way up to the neuropathology lab, where all of the slides and thousands of reports were stored in huge closets. This definitely was Kurt's kingdom, much quieter than the busy rooms of the neurology clinic. This was the place we met on a regular basis in the afternoons for the microscope 
sessions and where I (WP) learned in 1 year more about neuropathology than during the rest of my training. Kurt liked to dictate most of the reports himself-at an incredible speed - while beside him, the trainee looked down the multiheader microscope. Time was always precious, and it proved to be a highly efficient way of learning by just watching and listening to Kurt's dictate. Not only was it fascinating to unite clinical and morphological data, but it also greatly enhanced the understanding of neurological diseases, especially at a time before the broad availability of magnetic resonance imaging and high-quality computed tomography.

Kurt continued his effective way of teaching diagnostic neuropathology after retirement, as I (JA) experienced at first hand. In 2002, Kurt kindly agreed to help the Pathologic Bacteriologic Institute of the Otto Wagner Hospital, Vienna, in the diagnostic workup of postmortem brains, mainly from elderly demented and non-demented individuals. Kurt showed the trainees how to dissect formalinfixed brains. He literally proceeded with the dissection himself, at a time even with his left lower arm in plaster, as the trainees were just too slow for him and he was under constant time pressure. But maybe the true reason was that Kurt - to this very day-just loves dissecting brains (and hates waiting).

If one would wait for Kurt to suggest an idea or a topic for a possible collaborative publication or project, one would wait for a very long time; indeed, this trainee might still be waiting. However, when approached with a topic, Kurt decides within seconds: "Yes, you can do this" or "No, too bad, we can forget about this" would be the likely answers. If the project is started, Kurt helps here and there. I (JA) will never forget Kurt's words when I proudly announced that my first manuscript was finalized and asked him on a Tuesday afternoon if he would be so kind as to correct the manuscript. Kurt responded "Yes, send it to me, but I am not sure if I can read it before the weekend as I am very busy. Six talks in one month is even for me a bit too much." How great was my joy the next morning when I discovered the corrected manuscript in my e-mail inbox. Naturally, the manuscript was a mere shadow of its former self, but could be submitted the very same day and was published soon after. This story was chosen to illustrate the way Kurt helps: he does not engage in endless discussions about possible research; rather, he gives a preliminary "okay" and waits to see what the adept can achieve on his own. Whenever there are questions, those are answered with a plethora of recent literature to be digested and incorporated into the work by the pupil himself and any $\mathrm{draft} /$ manuscript is corrected at lightning speed.

Kurt frequently sends his protégés to scientific conferences. To clarify, "sending" sometimes meant that one was told that an abstract has already been submitted and accepted for presentation or that Kurt had accepted an invitation to give a talk months before. But it was more than once that the number of invitations went beyond the time he could spend off-duty. It was not for the plenary lectures, but, needless to say, that it was an incredible challenge for me (CB) to travel to international conferences, well-equipped with Kurt's "busy" slides to deliver the presentation instead of him. Should it happen, however, that you travel to a conference together with Kurt, be warned: as soon he sits in his seat in the airplane, he starts to read; usually, he has all sorts of things to read, such as books, scientific articles, and various newspapers. On a flight from Vienna to Philadelphia, I (JA) once sat beside Kurt-the aisle between us-and started to enjoy a movie. Kurt's expression was one of bewilderment when he discovered this: "What are you doing?" asked he, "Well, just watching movies, why not?" Disapproving murmur! After an hour, his frustration about the pupil wasting his time resulted in passing him an article across the aisle to stop between the pupil's eyes and the screen commanding: "Read this. This is very interesting!" Well, the pupil did so and many articles followed. Kurt himself, of course, never stopped reading for the whole flight to Philadelphia.

Kurt retired as a department head from Lainz Hospital in 1998; his scientific activity, however, has remained unchanged. Relieved from his clinical and administrative duties, he keeps on working and publishing at an astonishing pace. Indeed, he is definitely the fastest referee of Acta Neuropathologica (his reviews usually being submitted within $24 \mathrm{~h}$ ) and, right now, he is organizing a cluster of review articles for this journal. He presents his work at scientific meetings around the world and continues to work in his private neurology practice. Probably, he spends a little bit more time on his non-scientific passions, including going to concerts and hiking with his beloved wife Elisabeth. And he does not and will not rest on the fruits of his scientific work, thus, preserving his unsurpassed speed, efficiency, broad mindedness, and curiosity that keeps his mind as fresh as ever. 